\title{
The complex relationship between MITF and the immune system: a Melanoma ImmunoTherapy (response) Factor?
}

\author{
Robert Ballotti ${ }^{1,2}$, Yann Cheli ${ }^{1,2}$ and Corine Bertolotto ${ }^{1,2^{*}}$ (D)
}

\begin{abstract}
The clinical benefit of immune checkpoint inhibitory therapy (ICT) in advanced melanomas is limited by primary and acquired resistance. The molecular determinants of the resistance have been extensively studied, but these discoveries have not yet been translated into therapeutic benefits. As such, a paradigm shift in melanoma treatment, to surmount the therapeutic impasses linked to the resistance, is an important ongoing challenge. This review outlines the multifaceted interplay between microphthalmia-associated transcription factor (MITF), a major determinant of the biology of melanoma cells, and the immune system. In melanomas, MITF functions downstream oncogenic pathways and microenvironment stimuli that restrain the immune responses. We highlight how MITF, by controlling differentiation and genome integrity, may regulate melanoma-specific antigen expression by interfering with the endolysosomal pathway, KARS1, and antigen processing and presentation. MITF also modulates the expression of coinhibitory receptors, i.e., PD-L1 and HVEM, and the production of an inflammatory secretome, which directly affects the infiltration and/or activation of the immune cells.

Furthermore, MITF is also a key determinant of melanoma cell plasticity and tumor heterogeneity, which are undoubtedly one of the major hurdles for an effective immunotherapy. Finally, we briefly discuss the role of MITF in kidney cancer, where it also plays a key role, and in immune cells, establishing MITF as a central mediator in the regulation of immune responses in melanoma and other cancers.

We propose that a better understanding of MITF and immune system intersections could help in the tailoring of current ICT in melanomas and pave the way for clinical benefits and long-lasting responses.
\end{abstract}

\section{Treatments and resistance to treatments in melanoma}

Cutaneous melanoma is a malignant tumor that develops from melanocytes and affects patients of all ages. The global incidence in 2015 was estimated to be 350 , 000 , new cases $[1]$ and is constantly increasing while the mortality is stable or in discrete increase [2]. The increased incidence is probably due to the improved early detection of thin forms, while the incidence of thicker

\footnotetext{
* Correspondence: Corine.Bertolotto@univ-cotedazur.fr

'Université Côte d'Azur, Nice, France

${ }^{2}$ Inserm, Biology and Pathologies of melanocytes, team1, Equipe labellisée Ligue 2020 and Equipe labellisée ARC 2019, Centre Méditerranéen de Médecine Moléculaire, Nice, France
}

forms which have the greatest impact on mortality has remained stable. Prior to 2011, no treatment has demonstrated a significant impact on the overall survival of patients with metastatic melanoma.

The first therapeutic revolution in the management of melanomas followed the discovery of activating mutations in $B R A F$ (mainly $B R A F^{V 600 E}$ ) in approximately $50 \%$ of melanomas in 2002 [3]. BRAF ${ }^{\mathrm{V} 600 \mathrm{E}}$ has also been identified in papillary thyroid cancer, non-small cell lung cancer, colorectal cancers and serous ovarian carcinoma. Vemurafenib and dabrafenib, specific BRAF ${ }^{\mathrm{V} 600 \mathrm{E}}$ inhibitors, that do not inhibit wild type BRAF, were the first targeted therapies used in metastatic melanoma which produced a spectacular response rate of $60 \%$ for the first 
time. However, secondary resistance develops within a few months, resulting in a poor increase in median progression-free survival (5 to 7 months) with $\mathrm{BRAF}^{\mathrm{V} 600 \mathrm{E}}$ inhibitor treatment [4]. A combination of BRAF ${ }^{\mathrm{V} 600 \mathrm{E}}$ and MEK inhibitors, which is now the standard of care, gives rise to a better response rate that reaches 75\% [5] and delays the onset of resistance. Combination therapies therefore significantly prolonged median overall survival (up 25 months) and median progression-free survival (PFS) up to 12 months [6]. Despite this, resistance still occurs and worsens the clinical outcome of patients.

The second paradigm shift in melanoma treatment came from the use of monoclonal antibodies preventing the engagement of CTLA4 (Cytotoxic T-lymphocyteAssociated protein 4) or PD1 (Programmed Death protein 1), which are coinhibitory receptors expressed on the surface of T cells [7], with their ligands expressed on the surface of tumor cells. Anti-CTLA4 and anti-PD1 immune checkpoint inhibitor therapies (ICTs) prevent immune cell exhaustion and stimulate immune responses against tumor cells.

ICT has revolutionized the treatment of patients with cancer, to such an extent that Professors James Allison and Tasuko Honjo were awarded the 2018 Nobel Prize in Physiology or Medicine for their discovery of cancer therapy focused on inhibition of negative immune regulation. Adoptive T-cell therapy (ACT) can also induce durable antitumor responses due to the lasting memory feature of the adaptive immune system [8]. Interleukin 2 (IL-2), interferon, and oncolytic viral therapies can also have clinical benefits in melanoma, and they stand as alternatives for a subset of patients $[9,10]$.

ICTs have significantly improved outcomes for advanced-stage melanoma patients [11]. ICT agents show less impressive overall response rates $(40 \%$ for anti-PD1 therapy and 20\% for anti-CTLA4 therapy) than targeted therapies, while when combined they reach a response rate of more than $50 \%[12,13]$. More importantly, up to $40 \%$ of patients show a PFS after 4 years, indicating the development of long-lasting responses, and suggesting that this therapy may be a true cure. Nevertheless, these data also indicated that between 40 and $80 \%$ of patients display innate resistance to ICT and that when anti-CTLA4 and anti-PD1 antibodies are combined, at least $20 \%$ of patients develop secondary resistance. In addition, this drug combination can cause severe side effects.

There are multiple mechanisms of ICT resistance can be multiple, and their elucidation represents a challenge that researchers, clinicians and the pharmaceutical industry are facing now.

A complete deciphering of these mechanisms will allow the development of rationalized combinatorial treatments and further improve patients' overall survival.
A substantial amount of work has led to the identification of the mechanisms of resistance to ICT in melanomas and, more generally, solid cancers (for review see $[14,15]$. In brief, resistance can be ascribed to (i) a poor immunogenicity of the tumor, due to defective antigen expression or presentation in a context impairing immune cell activation, (ii) an altered T-cell trafficking to the tumor and (iii) reduced T-cell killing activity within the tumor. All these effects are mediated mainly by the tumor itself, but also by the tumor microenvironment (inflammation, hypoxia composition, matrix make-up, nutrient availability, etc.), composition of the immune infiltrate and by long-distance signaling arising from the gut microbiota.

\section{Pivotal role of MITF in the response of melanoma to immunotherapies}

Here, we focus our attention on intrinsic and melanoma specific mechanisms that could account for ICT therapy resistance and that would be amenable targets for new therapeutic strategies. Melanoma-specific mechanisms almost universally involve the MIcrophthalmiaassociated Transcription Factor (MITF). MITF comprises eight isoforms differentially expressed within various cell types and tissues [16]. The MITF-M isoform (hereafter simply designated as MITF) is the master regulator of melanocytes and has been identified as an addictive oncogene in melanoma [17-20].

The leading hypothesis in the field is that high MITF expression $\left(\right.$ MITF $\left.^{\text {high }}\right)$ is associated with a differentiated and proliferative phenotype, whereas low MITF expression $\left(\right.$ MITF $\left.^{\text {low }}\right)$, is associated with a dedifferentiated, invasive, apoptosis-resistant, and melanoma-initiating cell phenotype [21]. MITF $^{\text {high }}$ and MITF $^{\text {low }}$ cells coexist in melanoma tumors [22-24], and can originate from a reversible phenotypic switch that is responsible for melanoma plasticity and intratumor heterogeneity [25]. Signals in the tumor microenvironmental, such as hypoxia, nutrient availability and cytokines, that dampen MITF levels, can also favor the phenotypic transition [23, 2629]. Importantly, MITF has been shown to be instrumental in the response to targeted therapies, yet its role is complex given that both increased and decreased MITF expression can mediate resistance to BRAF inhibitors $[24,30,31]$. In addition, increasing evidence has been gathered, suggesting a role of MITF in the resistance to immunotherapy. This role in the resistance to immunotherapies is more ambiguous than in resistance to targeted therapies and has not yet been completely integrated by the community from therapeutic perspectives aimed at combatting resistance.

In this review, we focused our attention on MITF functions related to immunity, that could account for ICT resistance. 


\section{Role of MITF in antigen expression and presentation}

Antigens are recognized by $\mathrm{T}$ cells when they are displayed on cell surfaces by Major Histocompatibility Complex (MHC) molecules. Antigen presentation is carried out by antigen-presenting cells (APCs), the most important of which are dendritic cells (DCs), B cells and macrophages. Notably, some tumor cells including melanoma cells, can also be considered as APCs. MHC expression is controlled by interferon gamma (IFN $\gamma$ ), which is primarily produced by cells of the immune system and binds to the heterodimeric receptor complex, IFNGR1/IFNGR2, on tumor cells, activating the JAK1/2STAT1 signaling cascade [32]. Inactivating mutations in the antigen presentation pathway such as mutations in beta 2 microglobulin $(\beta 2 \mathrm{M})$ and JAK1/2 can influence the ability of melanoma cells to present peptides to the immune system. Loss-of-function mutations in JAK1/2 can lead to both primary and acquired resistance to anti-PD1 therapy [33, 34]. JAK mutations in tumor cells impair signaling initiated by IFN- $\gamma$, leading to acquired resistance to anti-PD1 therapy. Likewise, in primary resistance to anti-CTLA4 therapy, a relatively high frequency of mutations in several molecules involved in the interferon signaling pathway was reported [35].

If reduced MHC expression precludes efficient tumor cell recognition by T-cells, lack iofn antigen presentation is also a limiting step.

Indeed, MITF functions as a central regulator of melanocyte differentiation and melanogenesis by controlling the transcription of a panel of genes, including melan-A (MART1), tyrosinase and premelanosome protein PMEL17 (PMEL/SILV/gp100) [36-38], which encode proteins that have been reported to be tumor-specific antigens $[39,40]$.

Antigenic peptides are derived from proteins degraded by acidic proteases in the endolysosomal pathway. In melanomas, this function can also be assumed by specialized, lysosome-related organelles called melanosomes [40, 41]. Knowing that MITF drives endolysosomal and melanosomal biogenesis and functioning [42], MITF can affect antigen processing in addition to antigen production (Fig. 1).

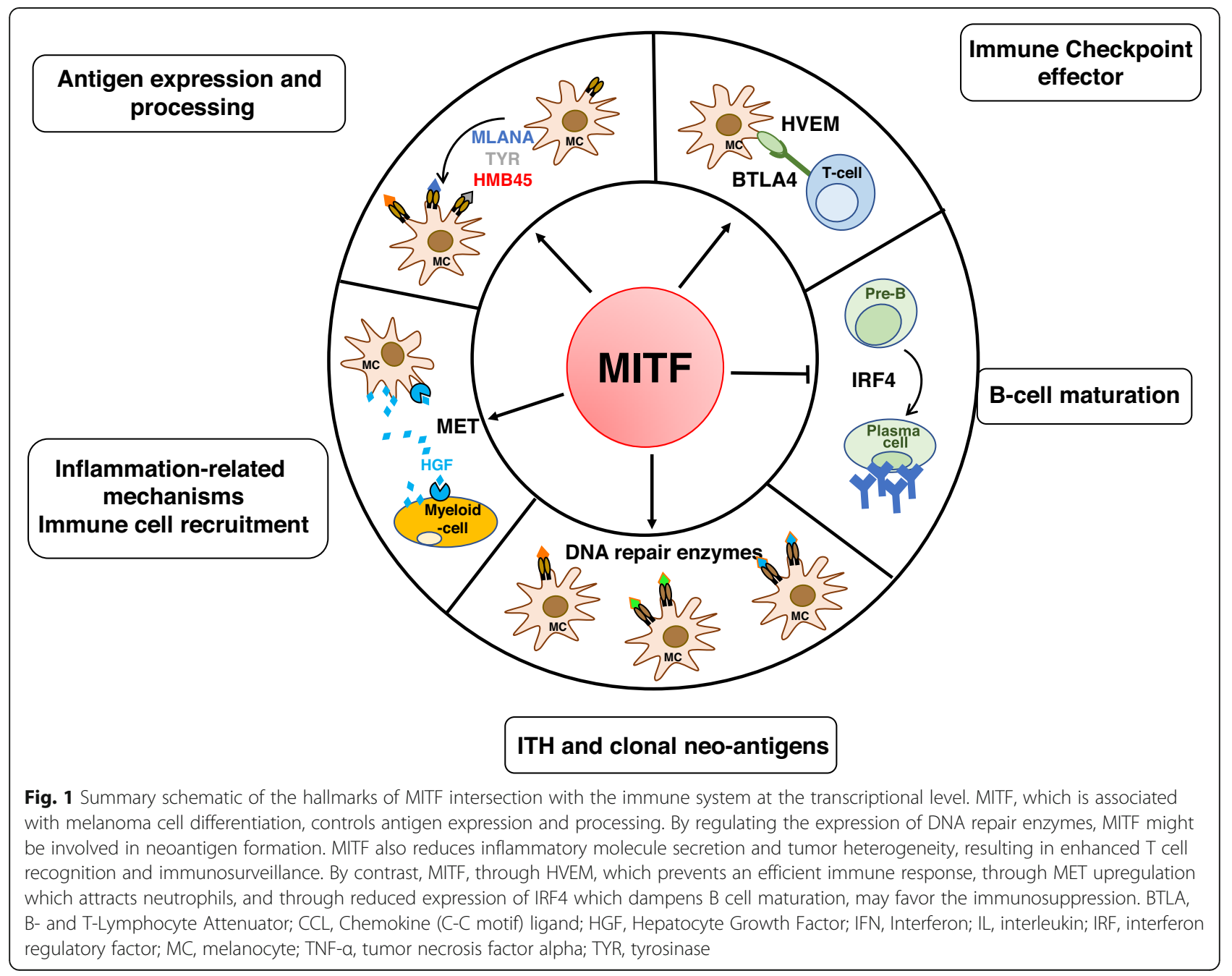


Supporting this idea, melanosomes and endolysosomes harbor distinct processing abilities that modify the presentation of MHC-restricted epitopes [40]. Since melanomas can lose their differentiated phenotype, in part due to downregulation of MITF expression, and subsequently no longer contain identifiable melanosomes, this change could affect antigen processing and presentation and influence immune recognition.

Consequently, any reduction in MITF expression should affect surface antigen presentation and recognition of melanoma cell recognition by the immune system.

\section{Roles of MITF in the mutational status and intratumor heterogeneity}

Tumor cells are genetically unstable, displaying the accumulation of somatic mutations in their genome, which is believed to increase the likelihood of immunogenic neoantigens expression by tumor cells and to favor $\mathrm{T}$ cell recognition. The high tumor mutational burden (TMB) in melanoma results from exposure to ultraviolet radiation (UV) radiation [43-45]. The TMB has emerged as a clinically relevant biomarker of ICT efficacy [46-49]. The higher the mutational burden is, the better the response to immune checkpoint inhibitors [50]. Patients with tumors, including cutaneous melanomas, harboring dysfunctional in DNA repair mechanisms, are better responders to anti-PD1 therapy than those with intact DNA repair mechanisms [51, 52]. A striking example is patients with uveal melanoma another type of melanoma, that is resistant to all immunotherapy regimens, however, a subset of patients, harboring inactivating mutations in methyl-CpG-binding domain protein 4 (MBD4) exhibit sensitivity to ICT $[53,54]$. MBD4 is involved in base excision repair, and those responding uveal melanomas are characterized by a high mutational burden. Mbd4-deficient mice, which display an enhanced mutation frequency, can be used to generate more physiopathological information on the roles of MBD4 in tumorigenesis and response to immune function [55-57]. Remarkably, MITF safeguards genomic stability through the transcriptional regulation of distinct DNA repair genes such as FANCA, BRCA1, POLE4 and POLD4, and MLH1 [37, 58-60], the last being a binding partner of MBD4 [61]. It is somewhat intuitive that the the phenotypic transition towards a MITF $^{\text {low }}$ state should therefore favor genomic instability, an increase in the umor mutational burden and the likelihood of neoantigen formation, rendering the cells more immunogenic. This is in contrast with data from the literature indicating that MITF $^{\text {low }}$ cells are more resistant to immunotherapies. This is likely because, MITF ${ }^{\text {low }}$ cells switch towards a dedifferentiated phenotype and harbor low expression of immunogenic target antigens, rendering them "poorly visible" for T cells. In addition, MITF ${ }^{\text {low }}$ cells produce a pro-inflammatory secretome, that could ultimately affect $\mathrm{T}$-cell recruitment and function (Fig. 1).

However, a high mutational load alone appears to be insufficient for producing clinical benefit. Indeed, some tumors showing a high mutational load do not respond to immunotherapy [62], whereas, tumors with a low mutational burden can respond well [63]. Importantly, not all neo-antigens are responsible for the formation of efficient CD8+ clones. In addition to accumulation of mutations and the generation of immunogenic neopeptides, genomic instability also allows the emergence of new less immunogenic new clones, that escape immune surveillance, and favor primary or acquired resistance. In line with that, UVB, the most common environmental risk factor for melanoma, enhances the neoantigen burdens, favoring melanoma aggressiveness [64]. Given that MITF has roles in DNA repair, ITH and the expression of differentiation antigens, a comprehensive understanding of its role in these processes is a major asset to better understand melanoma resistance to immunotherapies.

\section{Interactions of MITF and the pathways affecting the immune response of melanoma}

Specific oncogenic signals have been shown to mediate cancer immune evasion and resistance to immunotherapies, highlighting new putative targets for immune potentiation/rescue.

$\mathrm{BRAF}^{\mathrm{V} 600 \mathrm{E}}$, the most frequent mutation in cutaneous melanomas, downregulates the expression of MITF and its downstream effectors operating in the differentiation pathway, while MITF expression is increased by BRAF inhibitors [65, 66]. Given that MITF can impact on antigen presentation, this holds promise for the combination of targeted therapies with ICT. In humans, a the clinical trial (NCT02130466) revealed that triple-combination therapy (dabrafenib+trametinib+anti-PD1 antibody) increases the frequency of long-lasting antitumor responses in a subset of patients with $\mathrm{BRAF}^{\mathrm{V} 600}$-mutated metastatic melanomas [67]. Notably, in a preclinical model, a quadruple-combination therapy comprising dabrafenib, trametinib, an anti-PD-1 or anti-PD-L1 antibody and an immunostimulatory antibody specific for CD137 or anti-CD134 resulted in an effect superior to that of te triple-combination therapy [68].

Of interest, a screen of natural molecules related to aloperine led to the identification of SA-49, which induces a MITF dependent degradation of PD-L1 through the lysosomal pathway [69]. Therefore, targeted therapies, through increased MITF expression, may in turn decrease PD-L1 expression and improve the immune response and ICT efficacy (Fig. 2).

Hepatocyte growth factor (HGF), via stimulation of its cognate receptor c-MET, and activation of the downstream effector components (MAPK, STAT, PI3K-AKT 
cascades and NF-kB), increases the survival, motility and proliferation of several cell types of cancer cells, including melanoma cells. The role of HGF/MET signaling in the immune system in cancer is gaining attention since it could constitute a mechanism of primary and acquired resistance to cancer immunotherapy [70]. Autologous $\mathrm{T}$ cells expressing cMET CAR mRNA are being evaluated in patients with advanced melanoma or breast carcinoma in clinical trials (NCT03060356). Recently, some approaches have also been developed to combine MET and PD1/PD-L1 inhibition in locally advanced or metastatic hepatocarcinoma and renal cell carcinoma (NCT03655613 and NCT03672305). HGF can be produced by stromal cells and act on neutrophil recruitment [71] to limit therapeutic efficacy. High neutrophilto-lymphocyte ratios in patients with advanced cancer including melanoma generally correlate with a poor response to ICT and a poor prognosis [72-74]. HGF can also be secreted by the cancer cells themselves and exert its effect in an autonomous manner to regulate the expression of its own receptor in a MITF-dependent manner $[75,76]$. Upregulation of MET expression on tumor cells leads to an exacerbated HGF signaling and allows HGF to protect melanoma cells from apoptosis [75], highlighting a feed forward loop between HGF and cMET to favor treatment resistance (Fig. 1).

The PI3K/AKT pathway is also frequently activated in melanoma cells. One of the most common activation mechanisms is by loss of function of the tumor suppressor PTEN. PTEN loss often occurs in conjunction with BRAF mutation and is associated with relatively poor outcomes [77, 78]. PTEN-deficient melanoma cells tend to be less immunogenic than wild-type melanoma cells and are resistant to $\mathrm{T}$ cell-mediated immunotherapy [79]. One possible explanation is that the PI3K pathway, through increased BRN2 expression, dampens the level of MITF, and consequently inhibits the differentiated melanocytic phenotype [65, 80, 81]. Furthermore, PTEN deficient melanoma cells produce inhibitory cytokines such CCL2 and VEGF, that impede immune infiltration and $\mathrm{T}$ cell function. Interestingly, PI3K inhibitors and especially inhibitors of the PI3K $\beta$ isoform, could represent a new weapon against melanoma since they have been shown to improve the activity of both anti-PD1 antibodies and anti-CTLA4 antibodies in murine models [79]. Notably, PI3K inhibition has been reported to upregulate the expression of MITF level and differentiation antigens [82] (Fig. 2).

Downstream of PI3K, WNT/beta-catenin ( $\beta$-catenin) is another important signaling pathway that is implicated in many cancers including melanoma and which has been shown to play a key role in immune response [8385]. Tumor-intrinsic active $\beta$-catenin signaling, ensuing gain-of-function mutations in $\beta$-catenin, loss-of-function mutations in negative regulators of WNT signaling and increased expression of $\beta$-catenin effectors, result in $\mathrm{T}$ cell exclusion and "cold tumor" phenotype. The subset of melanomas with active $\beta$-catenin signaling shows resistance to ICT [86-88]. Trujillo et al., also have demonstrated that secondary resistance to immunotherapies might arise upon selection for strong tumor expression of $\beta$-catenin mediating tumor $\mathrm{T}$ cell exclusion from the

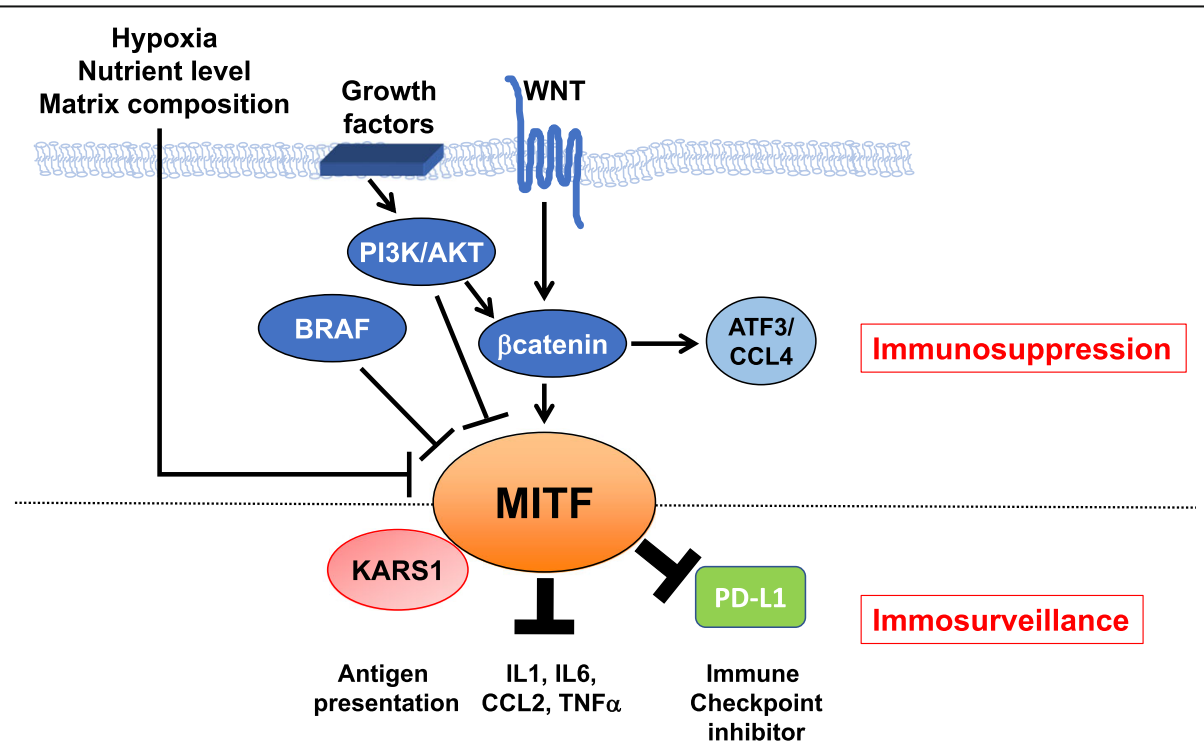

Fig. 2 Summary schematic of MITF regulation by oncogenic pathways and the intersection of MITF with the immune system at the posttranslational level. Oncogenic signaling pathways (WNT/B-catenin, PI3K/AKT and BRAF) in melanoma cells as well as the tumor microenvironment signals all converge to regulate MITF levels and/or activity and immune function, favoring immunosuppression. By interacting with KARS1, repressing PD-L1 expression and reducing cytokine secretion MITF favors immunosurveillance 
tumor [87]. The combination of $\mathrm{WNT} / \beta$-catenin signaling inhibitors with ICT may be a valid therapeutic option. Of interest, $\beta$-catenin regulates the transcription and expression of MITF in the melanocyte lineage and melanoma cells, potentially driving their differentiation or growth [27, 89-91]. Mechanistically, $\beta$-catenin can interact with Mitf in a Lef1-dependent [92], or Lef1independent [93] manner. It has been hypothesized that Mitf can redirect $\beta$-catenin transcriptional activity away from $\beta$-catenin/Lef1-regulated genes towards Mitfspecific target promoters, thereby diversifying the cellular behaviors. Remarkably, $\beta$-catenin signaling has also been reported to increase BRN2 expression via LEFbinding sites [94], and BRN2 represses MITF transcription $[65,80,81]$. Thus, $\beta$-catenin inhibition could switch the MITF level from high to low favoring dedifferentiation, and reduced immunogenicity (Fig. 2). Thus, while therapeutic options aimed at targeting $\mathrm{WNT} / \beta$-catenin signaling may hold promise to turn cold tumors into hot ones, they need to be considered with caution owing to a potential effects of reduced antigen presentation and the induction of an inflammatory TME induction due to MITF inhibition.

Mitf can also acts as a transcriptional repressor of genes involved in type I innate immune signaling in mouse melanocytes [95]. Although MITF binds and activates interferon regulator factor 4 (Irf4) in human melanocytes [96], and can transcriptionally regulate IFN signaling [97], regulation of the innate immune genes does not seem to involve Irf4. Upregulation of the expression of a fraction of these innate immune genes has also been observed in human melanoma cells treated with shRNA specific for MITF [98]. These findings strongly suggest a role for MITF in regulating the innate immune responses.

Immune responses are regulated by the engagement of costimulatory and coinhibitory receptor molecules. Immunotherapeutics targeting the inhibitory receptors CTLA-4, PD-1 or PD-L1 have achieved substantial clinical progress in cancer. However, a large proportion of patients remain unresponsive to these treatments, which may be due to the expression of other coinhibitory receptors on the surface of tumor infiltrating lymphocytes rendering anti-CTLA4 or anti-PD-1 monotherapy ineffective. Coinhibitory receptor targets that are being explored in clinical trials include LAG-3, TIM-3, TIGIT and HVEM $[99,100]$. Some of these coreceptors have already been targeted in clinical trials (ClinicalTrials. gov). Specifically, Herpes Virus Entry Mediator (HVEM, also known as TNFRSF14), a member of the TNF receptor superfamily and thought to be primarily expressed on hematopoietic cells, has also been described to be expressed on melanoma cells [101]. Metastatic melanoma patients, with a high HVEM expression, have a significantly poorer overall survival than those with low HVEM expression [102]. HVEM on melanoma cells inhibits the proliferation and production of IFNY by Band T-lymphocyte attenuator (BTLA)-positive tumorspecific CD8 T-cells. BTLA is an immunoregulatory receptor, similar to CTLA-4 and PD-1, and is mainly expressed on $\mathrm{B}$ cells, $\mathrm{T}$ cells and all mature lymphocytes [103]. These results suggest the transduction of inhibitory signals caused by HVEM/BTLA interactions. Importantly, HVEM was recently reported to be a target gene of MITF [102], indicating that MITF also regulates antimelanoma immune responses at the level of the regulatory function of coinhibitory receptors. In this case, MITF would favor immune cell exhaustion. Thus, anti-BTLA therapy warrants investigation in patients resistant to anti-CTLA4 or anti-PD1 therapy (Fig. 1).

\section{The tumor microenvironment}

There is growing evidence that the production of cytokines or other factors in the tumor microenvironment decreases T-cell expansion and function and may help melanoma cells to resist elimination by $\mathrm{T}$ lymphocytes.

For instance, the immune cell-rich microenvironment driven by tumor-initiated inflammation promotes melanoma dedifferentiation and overrides protective adaptive immunity [104, 105]. Consistently, a previous study indicated that an inflammatory milieu induces melanoma dedifferentiation, illustrated by a reduction in the levels of melanocytic antigens, and favors immunotherapy resistance [106].

Mechanistically, $\mathrm{T}$ cell-driven inflammatory stimuli such as TNF- $\alpha$, engage the transcription factor c-jun in tumor cells, which in turn reduces MITF levels, and consequently decreases the expression of melanocyte differentiation genes, thereby leading to melanoma cell dedifferentiation [107]. This is reminiscent of a previous report demonstrating that TNF- $\alpha$, via activation of $\mathrm{NF} \kappa \mathrm{B}$, reduces the expression of melanocyte differentiation genes, likely through decreased MITF expression [108]. These observations support the idea of intervening with anti-TNF- $\alpha$ antibodies. Consistent with this, nivolumab+ipilimumab in combination with the anti-TNF- $\alpha$ antibody certolizumab has been studied in advanced melanoma in clinical trial (NCT03293784) [109].

Other cytokines such as IFN- $\gamma$, IL-1 $\beta$, IL-6 and CCL2, produced by the TME also induce dedifferentiation and phenotypic transition as well. IFN- $\gamma$, which is released by $\mathrm{T}$ cells and tumor-infiltrating myeloid immune cells, also diminishes the mRNA levels of melanocyte differentiation antigens [110]. Further work is required to determine how IFN- $\gamma$ functions to affect melanocyte differentiation antigens, this process might involve the downregulation of MITF expression [111]. Likewise, IL$1 \beta$ strongly reduces the expression of MITF and 
melanocyte differentiation antigens. This translates into a reduced recognition of melanoma cells by cytolytic $\mathrm{T}$ lymphocytes [112]. Mechanistically, IL-1 $\beta$ inhibits MITF through microRNA-155 [113].

It is well known that some of these factors can also be secreted by melanoma cells themselves. MITF may be involved in this production. Indeed, compared to MITFpositive cells, the MITF-negative cells produce larger amounts of IL- $1 \alpha$ and IL- $1 \beta$. Furthermore, the supernatant of MITF-negative melanoma cells reduces MITF expression in positive cells. This effect is blocked by the IL-1 receptor antagonist IL-1Ra [112].

In agreement with the above information, genetic suppression of MITF in melanoma cells (siRNA-mediated MITF knockdown) triggers an inflammatory secretome comprising the abovementioned cytokines [28, 60, 114]. Naive melanoma cells exposed to the inflammatory secretome of MITF-depleted cells switch towards a dedifferentiated phenotype with a reduced immunogenicity ability that could contribute to escape from immune responses. This phenotype can partially be rescued by anti-CCL2 neutralizing antibodies [114]. MITF inhibits the promoter activity of CCL2, suggesting that MITF controls the expression of a CCL2 repressor [114]. Likewise, IL6 via activation of the JAK/STAT3 signaling pathway induces a sharp decrease in the levels of MITF and its upstream regulator PAX3, both of which are associated with dedifferentiation [115]. Collectively, these observations implicate MITF in the regulation of cytokine production and suggest the existence of a negativefeedback loop between MITF, IL1 and the CCL2 family of cytokines. Oncogenic BRAF, through decreased MITF expression and enhanced IL- $1 \alpha$ and IL- $1 \beta$ secretion, triggers PD-L1 and PD-L2 expression in tumorassociated fibroblasts which also contributes to suppression of tumor-infiltrating $\mathrm{T}$ cell function [116].

Notably, that there is greater immune infiltration in MITF $^{\text {low }}$ tumors than in MITF ${ }^{\text {high }}$ tumors. This is likely because MITF regulates the key lipogenic enzyme stearoyl-CoA desaturase (SCD) [27]. Low SCD levels leads to inflammatory signaling and immune cell recruitment, although dedifferentiated MITF ${ }^{\text {low }}$ cells are not responsive to immune function. Thus, enhancing the MITF-SCD axis which suppresses inflammatory signaling, may represent a therapeutic strategy to improve ICT outcomes.

Variations in other microenvironmental cues, including hypoxia, matrix composition, nutrient levels and the microbiota, can also influence the therapeutic response to ICT. Crucially, the transcriptomic profiles of anti-PD1 monotherapy nonresponders exhibit upregulation of the expression of the hypoxic marker, carbonic anhydrase 9 [117], which is a known cancer progression marker [118]. In line with this, hypoxia reduces MITF levels [23,
119], an effect in part mediated through the transcriptional repressor bHLHb2 [23].

Tumor metabolism shapes antitumor immune responses [120]. Several lines of evidence indicate that metabolic changes regulate MITF levels and thus may impact on melanoma immunogenicity $[26,27,29,121]$. Melanoma cells can also express the enzyme indoleamine 2,3-dioxygenase (IDO) in response to IFN- $\gamma$. IDO contributes to immunosuppression by catalyzing the degradation of tryptophan into kynurenine which causes an inhibition of effector $T$ cell functions [122]. Notably, the kynurenine pathway is essential for the de novo synthesis of $\mathrm{NAD}^{+}$. Importantly, increased NAD+ levels render $\mathrm{BRAF}^{\mathrm{V} 600 \mathrm{E}}$ melanoma cells resistant to vemurafenib and this was associated with epigenetic changes and reduced MITF expression [121]. One can thus envision that increased NAD+ levels, favors MITF downregulation, thereby supporting ICT resistance.

In conclusion, MITF loss drives melanoma cell plasticity and phenotypic switching that correlates with reduced differentiation and immunogenicity, this loss also limits antitumor efficacy through the production of an inflammatory milieu that shapes an immunosuppressive TME.

Finally, several lines of evidence also support the key role of the gut microbiota in the control of tumor growth and response to therapy [123-126]. The gut microbiome composition could predict treatment response and may contribute to immune responses. Thus, modulating the gut microbiome in patients receiving ICT (antibiotics, prebiotics, or bacterial introduction, or of bacterial metabolic byproducts such as short-chain fatty acids or conjugated bile acids) offers a new therapeutic strategy in patients with primary resistance and could nicely complement established treatments for melanoma. Whether MITF can impact on the microbiota composition or vice versa has yet to be demonstrated.

\section{Roles of MITF in nonmelanoma cells}

As mentioned earlier, whereas the M-isoform of MITF is specifically expressed in the melanocyte lineage, MITF comprises other isoforms expressed within various cell types.

The MITF E318K germline mutation predisposes to melanoma, but also renal cell carcinoma (RCC) [17]. A rare subtype of RCC, translocation renal cell carcinoma (tRCC), which occurs in patients before 40 years, harbors specific translocations of TFE3, TFEB and MITF leading to their overexpression [127]. tRCC displays relatively aggressive behavior and appears resistant to immune checkpoint inhibitors after a first-line treatment with tyrosine kinase inhibitors [128]. Hence, in the context of RCC, high MITF levels appear to be associated with ICT resistance. 
Dendritic cells, the most potent APCs, express MITF. An interaction between MITF and the lysyl-tRNA synthetase (KARS1) has been reported to stimulate MITF transcriptional activity through the generation of diadenosine tetraphosphate (Ap4A), which is also a key regulator of antigen presentation [129]. Thus, MITF can influence the initiation and maintenance of primary immune responses. Furthermore, mast cells also play an important role in both innate and adaptive immunity [130, 131]. Interestingly, MITF is required for their proper development and function, notably through regulating KIT expression [132]. It is worth noting that the regulation of KIT by MITF in melanocytes and melanoma cells remains to be clearly demonstrated, indicating that a tissue specific regulation of KIT by MITF in mast cells might be explained by expression of lineage-restricted cofactors.

Furthermore, in naive B cells, MITF represses IRF4, a critical regulator of various aspects of $\mathrm{B}$ - and $\mathrm{T}$ cell maturation [133, 134]. In mice, Mitf antagonizes the process of B cell terminal differentiation into antibody secreting plasma cells. Conversely, defective Mitf activity results in spontaneous B cell activation and antibody production [135]. Thus, the MITF level or MITF activity can also affect $\mathrm{T}$ and $\mathrm{B}$ cell maturation.

Interestingly, MITF has been reported to play a key role in immune defense in the mollusc clam, Meretrix petechialis. Although not related to the cancer field, this model can provide robust insights into how MITF functions in immunity [136].

\section{Conclusion}

Although it is clear that MITF has a role in immune cell trafficking and function, its roles are complex and, as it is often the case with MITF, is marked by a certain duality. Indeed, MITF loss was expected to reduce differentiation and antigen expression, thereby decreasing immunogenicity. Immunogenicity can be restored by reintroducing differentiation antigens as it has been done by using nanoparticulate liposomal RNA vaccine encoding tumor-associated antigens such as tyrosinase. This strategy has recently demonstrated a durable objective response in ICT-treated patients with advanced melanomas [137]. Furthermore, given that MITF $^{\text {low }}$ melanoma cells produce an inflammatory secretome [114], identification and targeting of factors and/or chemokines in this secretome, preventing antitumour immunity, could also improve response to ICT. In line with this, transient MITF knockdown, leads to decreased immune cell recruitment in B16 melanoma tumors [138]. However, in the TCGA cohort, MITF ${ }^{\text {low }}$ tumors displayed an increased immune cell infiltrate that could be explained by a consequent downregulation of SCD expression [27]. Whether this immune infiltrate has a fully functional cytotoxic function remains to be studied.
Also of interest is the peculiar link between MITF and KARS1, which operates in melanocytes and other cell types such as DCs [139-141] (Fig. 2).

The most striking links between MITF and the immune responses were identified in a recent study using four syngeneic models recapitulating diverse subtypes of human melanoma and the diversity of clinical responses to ICT. This study pointed out to a melanocytic plasticity signature predictive of patient outcomes in response to immune checkpoint blockade [142]. The study results also suggest that a high differentiation status in melanoma predicts ICT benefit. In particular, the expression of several MITF target genes was upregulated in the differentiation signature, however, that of MITF, whose activity can be regulated by posttranslational events, such as those mediated by KARS1, rather than at the transcriptional level, was not. In agreement with these observations, analysis of the transcriptomic signature of melanoma patients according to their response to antiPD1 therapy also identified a dedifferentiation signature (downregulation of MITF target gene expression) associated with a lack of response to the treatment [143].

Therefore, accumulating evidence indicates that MITF has an important impact on immune function and the response to ICT, acting both on tumor immunogenicity and in shaping the immunological TME. Although, MITF favors melanoma proliferation, it might be worth evaluating the effects of agents that increase MITF expression on the response to ICT. Such agents include alpha-melanocyte-stimulating hormone $(\alpha-\mathrm{MSH})$ and cAMP-elevating agents, such as forskolin that were reported to increase the levels of MITF and melanoma antigens such as MART-1 and GP-100 [144, 145]. These treatments are expected to increase the recognition of melanoma cells by $\mathrm{T}$ cells and improve the immune response. Similar results may be obtained with methotrexate [146]. In summary, one of the main hurdles to achieving fully effective immunotherapy is the plasticity of melanoma cells, in which MITF plays a pivotal role. This plasticity makes of melanoma a moving target that is difficult to target with the immune system. Therefore, freezing melanoma cells in one phenotypic state, preferably the differentiation state, may be of interest to facilitate antitumor effects by the immune system.

Finally, it may be reasonable to develop CAR-T cells targeting proteins highly expressed in dedifferentiated melanoma, such as AXL, whose expression is clearly inversely correlated with that of MITF.

In conclusion, it may be wise to include MITF in the pipeline of reflection aimed at finding rationalized and personalized treatments, that combine multimodal therapeutic approaches with ICT to prevent resistance relapse and generate long-term survival benefits. 


\section{Abbreviations}

ACT: Adoptive T-cell Therapy; APC: Antigen-presenting cells; AKT (PKB): Protein Kinase B; $\beta 2$ M: beta 2 microglobulin; bHLHB2: basic Helix Loop Helix protein class B2; BRAF: B-Raf Proto-Oncogene; BRCA1: BReast CAncer 1; BTLA: B- and T-Lymphocyte Attenuator; CCL2: Chemokine Ligand 2; CTLA4: Cytotoxic T-Lymphocyte-Associated protein 4; DC: Dendritic Cells; FANCA: FANConi anemia group A protein; HGF: Hepatocyte Growth Factor; HVEM: Herpes Virus Entry Mediator; ICT: Immune Checkpoint inhibitory Therapy; IL: Interleukin; IFN: Interferon; IFNGR: Interferon gamma receptor; ITH: IntraTumor Heterogeneity; IRF4: Interferon Regulatory Factor 4; JAK: Janus Kinase; KARS: Lysine-tRNA ligase; LAG3: Lymphocyte-Activation Gene 3; LEF1: Lymphoid Enhancer Binding Factor 1; NAD: Nicotinamide adenine dinucleotide; MAPK: Mitogen Activated Protein Kinase: MART1: melanoma antigen recognized by T cells 1; MHC: Major Histocompatibility Complex; MBD4: Methyl-CpG Binding Domain 4; MITF: MIcrophthalmia-associated Transcription Factor; MLH1: MutL Homolog 1; NFkB: Nuclear Factor kappa B; PD1: Programmed Death protein 1; PDL1: Programmed Death-Ligand 1; POLD4: Polymerase (DNA-directed) delta 4; POLE4: Polymerase (DNA-directed) epsilon 4; PMEL17: PreMELanosome protein; PTEN: Phosphatase and TENsin homolog; RCC: Renal Cell Carcinoma; SCD: Stearoyl-COA Desaturase; STAT: Signal Transducer and Activator of Transcription; TCGA: The Cancer Genome Atlas; TFEB: Transcription Factor EB; TFE3: Transcription Factor E3; TIGIT: T cell immunoreceptor with IG and ITIM domains; TIM-3: T-cell Immunoglobulin and Mucin-domain containing-3; TNF: Tumor Necrosis Factor; TME: Tumor microenvironment; TMB: Tumor Mutational Burden; UV: Ultraviolet; WNT: Wingless

\section{Acknowledgements}

Not applicable.

\section{Authors' contributions}

C.B., R.B. and Y.C. wrote the manuscript. The author(s) read and approved the final manuscript.

\section{Authors' information \\ None.}

\section{Funding}

This work was funded by INCa grant INCa_10573 to CB and La Société Française de Dermatologie.

\section{Availability of data and materials}

Not applicable.

\section{Ethics approval and consent to participate}

Not applicable.

\section{Consent for publication}

All authors consent to the publication of the manuscript in Molecular Cancer.

\section{Competing interests}

The authors declare no conflict of interest.

Received: 6 October 2020 Accepted: 29 November 2020

Published online: 05 December 2020

\section{References}

1. Karimkhani C, Green AC, Nijsten T, Weinstock MA, Dellavalle RP, Naghavi M, et al. The global burden of melanoma: results from the global burden of disease study 2015. Br J Dermatol. 2017;177:134-40.

2. Cho H, Mariotto AB, Schwartz LM, Luo J, Woloshin S. When do changes in cancer survival mean progress? The insight from population incidence and mortality. J Natl Cancer Inst. 2014;2014:187-97.

3. Davies H, Bignell GR, Cox C, Stephens P, Edkins S, Clegg S, et al. Mutations of the BRAF gene in human cancer. Nature. 2002;417:949-54.

4. Johnson DB, Menzies AM, Zimmer L, Eroglu Z, Ye F, Zhao S, et al. Acquired BRAF inhibitor resistance: a multicenter meta-analysis of the spectrum and frequencies, clinical behaviour, and phenotypic associations of resistance mechanisms. Eur J Cancer. 2015;51:2792-9.
5. Long GV, Stroyakovskiy D, Gogas H, Levchenko E, de Braud F, Larkin J, et al. Combined BRAF and MEK inhibition versus BRAF inhibition alone in melanoma. N Engl J Med. 2014;371:1877-88.

6. Long GV, Flaherty KT, Stroyakovskiy D, Gogas H, Levchenko E, de Braud F, et al. Dabrafenib plus trametinib versus dabrafenib monotherapy in patients with metastatic BRAF V600E/ K-mutant melanoma: Long-term survival and safety analysis of a phase 3 study. Ann Oncol. 2017;28:1631-9.

7. Brunet JF, Denizot F, Luciani MF, Roux-Dosseto M, Suzan M, Mattei MG, et al. A new member of the immunoglobulin superfamily-CTLA-4. Nature. 1988;328:267-70.

8. Yang JC, Rosenberg SA. Adoptive T-Cell therapy for cancer. Adv Immunol. 2016;130:279-294.

9. Urbani F, Ferraresi V, Capone I, Macchia I, Palermo B, Nuzzo C, et al. Clinical and immunological outcomes in high-risk resected melanoma patients receiving peptide-based vaccination and interferon alpha, with or without Dacarbazine preconditioning: a phase II study. Front Oncol. 2020;10:202. https://doi.org/10.3389/fonc.2020.00202.

10. Bayan C-AY, Lopez AT, Gartrell RD, Komatsubara KM, Bogardus M, Rao N, et al. The role of Oncolytic viruses in the treatment of melanoma. Curr Oncol Rep. 2018;20:80.

11. Hodi FS, Chiarion-Sileni V, Gonzalez R, Grob JJ, Rutkowski P, Cowey CL, et al. Nivolumab plus ipilimumab or nivolumab alone versus ipilimumab alone in advanced melanoma (CheckMate 067): 4-year outcomes of a multicentre, randomised, phase 3 trial. Lancet Oncol. 2018;19:1480-92.

12. Asmar R, Yang J, Carvajal RD. Clinical utility of nivolumab in the treatment of advanced melanoma. Ther Clin Risk Manag. 2016;12:313-25.

13. Larkin J, Chiarion-Sileni V, Gonzalez R, Grob JJ, Rutkowski P, Lao CD, et al. Five-year survival with combined nivolumab and ipilimumab in advanced melanoma. N Engl J Med. 2019;381:1535-46.

14. Koustas E, Sarantis P, Papavassiliou AG, Karamouzis MV. The resistance mechanisms of checkpoint inhibitors in solid tumors. Biomolecules. 2020;10:1-17.

15. Sharma P, Hu-Lieskovan S, Wargo JA, Ribas A. Primary, adaptive, and acquired resistance to Cancer immunotherapy. Cell. 2017;168:707-23.

16. Goding CR, Arnheiter H. MITF — the first 25 years. Genes Dev. 2019;33:983-1007.

17. Bertolotto C, Lesueur F, Giuliano S, Strub T, De Lichy M, Bille K, et al. A SUMOylation-defective MITF germline mutation predisposes to melanoma and renal carcinoma. Nature. 2011;480:94-8.

18. Bonet C, Luciani F, Ottavi J-F, Leclerc J, Jouenne F-M, Boncompagni M, et al. Deciphering the role of oncogenic MITF ${ }^{\mathrm{E} 318 \mathrm{~K}}$ in senescence delay and melanoma progression. J Natl Cancer Inst. 2017;109. https://doi.org/10.1093/ jnci/djw340.

19. Garraway LA, Widlund HR, Rubin MA, Getz G, Berger AJ, Ramaswamy S, et al. Integrative genomic analyses identify MITF as a lineage survival oncogene amplified in malignant melanoma. Nature. 2005;436:117-22.

20. Yokoyama S, Woods SL, Boyle GM, Aoude LG, MacGregor S, Zismann V, et al. A novel recurrent mutation in MITF predisposes to familial and sporadic melanoma. Nature. 2011;480:99-103.

21. Hoek KS, Goding CR. Cancer stem cells versus phenotype-switching in melanoma. Pigment Cell Melanoma Res. 2010;23:746-59.

22. Cheli Y, Giuliano S, Botton T, Rocchi S, Hofman V, Hofman P, et al. Erratum: Mitf is the key molecular switch between mouse or human melanoma initiating cells and their differentiated progeny. Oncogene. 2011;30:2307-18.

23. Cheli Y, Giuliano S, Fenouille N, Allegra M, Hofman V, Hofman P, et al. Hypoxia and MITF control metastatic behaviour in mouse and human melanoma cells. Oncogene. 2012;31:2461-70.

24. Muller J, Krijgsman O, Tsoi J, Robert L, Hugo W, Song C, et al. Low MITF/AXL ratio predicts early resistance to multiple targeted drugs in melanoma. Nat Commun. 2014;:5:983-1007.

25. Rambow F, Marine J, Goding CR. Melanoma plasticity and phenotypic diversity : therapeutic barriers and opportunities. Genes Dev. 2019;33:1295-318.

26. Falletta P, Sanchez-Del-Campo L, Chauhan J, Effern M, Kenyon A, Kershaw CJ, et al. Translation reprogramming is an evolutionarily conserved driver of phenotypic plasticity and therapeutic resistance in melanoma. Genes Dev. 2017;31:18-33.

27. Vivas-García Y, Falletta P, Liebing J, Louphrasitthiphol P, Feng Y, Chauhan J, et al. Lineage-restricted regulation of SCD and fatty acid saturation by MITF controls melanoma phenotypic plasticity. Mol Cell. 2020;77:120-37.

28. Ohanna M, Cheli Y, Bonet C, Bonazzi VF, Allegra M, Giuliano S, et al. Secretome from senescent melanoma engages the STAT3 pathway to favor reprogramming of naive melanoma towards a tumor-initiating cell phenotype. Oncotarget. 2013;4:2212-24. 
29. Leclerc J, Garandeau D, Pandiani C, Gaudel C, Bille K, Nottet N, et al. Lysosomal acid ceramidase ASAH1 controls the transition between invasive and proliferative phenotype in melanoma cells. Oncogene. 2019;38:1282-95.

30. Johannessen CM, Johnson LA, Piccioni F, Townes A, Frederick DT, Donahue MK, et al. A melanocyte lineage program confers resistance to MAP kinase pathway inhibition. Nature. 2013;504:138-42.

31. Smith MP, Ferguson J, Arozarena I, Hayward R, Marais R, Chapman A, et al. Effect of SMURF2 targeting on susceptibility to MEK inhibitors in melanoma. J Natl Cancer Inst. 2013;105:33-46.

32. Platanias LC. Mechanisms of type--- and type-II-interferon-mediated signalling. Nat Rev Immunol. 2005;5:375-86.

33. Shin DS, Zaretsky JM, Escuin-Ordinas H, Garcia-Diaz A, Hu-Lieskovan S, Kalbasi A, et al. Primary resistance to PD-1 blockade mediated by JAK1/2 mutations. Cancer Discov. 2017;7:188-201

34. Zaretsky JM, Garcia-Diaz A, Shin DS, Escuin-Ordinas H, Hugo W, HuLieskovan S, et al. Mutations associated with acquired resistance to PD-1 blockade in melanoma. N Engl J Med. 2016;375:819-29.

35. Gao J, Shi LZ, Zhao H, Chen J, Xiong L, He Q, et al. Loss of IFN- $\gamma$ pathway genes in tumor cells as a mechanism of resistance to anti-CTLA-4 therapy. Cell. 2016;167:397-404.

36. Strub T, Giuliano S, Ye T, Bonet C, Keime C, Kobi D, et al. Essential role of microphthalmia transcription factor for DNA replication, mitosis and genomic stability in melanoma. Oncogene. 2011;30:2319-32.

37. Hoek KS, Schlegel NC, Eichhoff OM, Widmer DS, Praetorius C, Einarsson SO, et al. Novel MITF targets identified using a two-step DNA microarray strategy. Pigment Cell Melanoma Res. 2008;21:665-76.

38. Du J, Miller AJ, Widlund HR, Horstmann MA, Ramaswamy S, Fisher DE. MLANA/MART1 and SILV/PMEL17/GP100 are transcriptionally regulated by MITF in melanocytes and melanoma. Am J Pathol. 2003;163:333-43.

39. Michaeli Y, Sinik K, Haus-Cohen M, Reiter Y. Melanoma cells present high levels of HLA-A2-tyrosinase in association with instability and aberrant intracellular processing of tyrosinase. Eur J Immunol. 2012;42:842-50.

40. Robila V, Ostankovitch M, Altrich-VanLith ML, Theos AC, Drover S, Marks MS, et al. MHC class II presentation of gp100 epitopes in melanoma cells requires the function of conventional endosomes and is influenced by Melanosomes. J Immunol. 2008;181:7843-52

41. Orlow SJ. Melanosomes are specialized members of the lysosomal lineage of organelles. J Invest Dermatol. 1995;105:3-7.

42. Ploper D, Taelman VF, Robert L, Perez BS, Titz B, Chen HW, et al. MITF drives endolysosomal biogenesis and potentiates Wnt signaling in melanoma cells. Proc Natl Acad Sci U S A. 2015;112:E420-9.

43. Hodis E, Watson IR, Kryukov GV, Arold ST, Imielinski M, Theurillat JP, et al. A landscape of driver mutations in melanoma. Cell. 2012;150:251-63.

44. Berger MF, Hodis E, Heffernan TP, Deribe YL, Lawrence MS, Protopopov A, et al. Melanoma genome sequencing reveals frequent PREX2 mutations. Nature. 2012:485:502-6.

45. Krauthammer $\mathrm{M}$, Kong $\mathrm{Y}, \mathrm{Ha}$ BH, Evans $\mathrm{P}$, Bacchiocchi A, McCusker JP, et al. Exome sequencing identifies recurrent somatic RAC1 mutations in melanoma. Nat Genet. 2012:44:1006-14.

46. Hu-lieskovan S, Berent-maoz B, Pang J, Chmielowski B, Cherry G, Seja E, et al. Genomic and Transcriptomic features of response to anti-PD-1 therapy in metastatic melanoma. Cell. 2017;165:35-44.

47. Van Allen EM, Miao D, Schilling B, Shukla SA, Blank C, Zimmer L, et al. Erratum for the report "genomic correlates of response to CTLA-4 blockade in metastatic melanoma.". Science. 2016;352:207-12.

48. Gubin MM, Zhang X, Schuster H, Caron E, Ward JP, Noguchi T, Ivanova Y, Hundal J, Arthur CD, Krebber WJ, Mulder GE, Toebes M, Vesely MD, Lam SSK, Korman J, Allison JP, et al. Checkpoint blockade Cancer immunotherapy targets tumour- specific mutant antigens. Nature. 2015;515: 577-581. A.

49. Samstein RM, Lee $C H$, Shoushtari AN, Hellmann MD, Shen R, Janjigian $Y Y$, et al. Tumor mutational load predicts survival after immunotherapy across multiple cancer types. Nat Genet. 2019;51:202-6.

50. Yarchoan M, Hopkins A, Jaffee EM. Tumor mutational burden and response rate to PD-1 inhibition. N Engl J Med. 2017;377:2500-1.

51. Le DT, Uram JN, Wang H, Bartlett BR, Kemberling H, Eyring AD, et al. PD-1 blockade in tumors with mismatch-repair deficiency. N Engl J Med. 2016; 372:2509-20.

52. Germano G, Lamba S, Rospo G, Barault L, Magri A, Maione F, et al. Inactivation of DNA repair triggers neoantigen generation and impairs tumour growth. Nature. 2017:552:1-5.
53. Johansson PA, Stark A, Palmer JM, Bigby K, Brooks K, Rolfe O, et al. Correction to: prolonged stable disease in a uveal melanoma patient with germline MBD4 nonsense mutation treated with pembrolizumab and ipilimumab. Immunogenetics. 2019;71:433-6.

54. Rodrigues M, Mobuchon L, Houy A, Fiévet A, Gardrat S, Barnhill RL, et al. Outlier response to anti-PD1 in uveal melanoma reveals germline MBD4 mutations in hypermutated tumors. Nat Commun. 2018;9:1-6.

55. Cortellino S, Turner D, Masciullo V, Schepis F, Albino D, Daniel R, et al. The base excision repair enzyme MED1 mediates DNA damage response to antitumor drugs and is associated with mismatch repair system integrity. Proc Natl Acad Sci U S A. 2003;100:15071-6.

56. Millar CB, Guy J, Sansom OJ, Selfridge J, MacDougall E, Hendrich B, et al. Enhanced CpG mutability and tumorigenesis in MBD4-deficient mice. Science. 2002;297:403-5.

57. Wong E, Yang K, Kuraguchi M, Werling U, Avdievich E, Fan K, et al. Mbd4 inactivation increases $\mathrm{C} \rightarrow T$ transition mutations and promotes gastrointestinal tumor formation. Proc Natl Acad Sci U S A. 2002;99:14937-42.

58. Beuret L, Ohanna M, Strub T, Allegra M, Davidson I, Bertolotto C, et al. BRCA1 is a new MITF target gene. Pigment Cell Melanoma Res. 2011;24: 725-7.

59. Bourseguin J, Bonet C, Renaud E, Pandiani C, Boncompagni M, Giuliano S, et al. FANCD2 functions as a critical factor downstream of MiTF to maintain the proliferation and survival of melanoma cells. Sci Rep. 2016;6:36539.

60. Giuliano S, Cheli Y, Ohanna M, Bonet C, Beuret L, Bille K, et al. Microphthalmia-associated transcription factor controls the DNA damage response and a lineage-specific senescence program in melanomas. Cancer Res. 2010;70:3813-22.

61. Bellacosa A, Cicchillitti L, Schepis F, Riccio A, Yeung AT, Matsumoto Y, et al. MED1, a novel human methyl-CpG-binding endonuclease, interacts with DNA mismatch repair protein MLH1. Proc Natl Acad Sci U S A. 1999;96: 3969-74.

62. Snyder A, Makarov V, Merghoub T, Yuan J, Zaretsky JM, Desrichard A, et al. Genetic basis for clinical response to CTLA-4 blockade in melanoma. N Engl J Med. 2014:371:2189-99.

63. Miao D, Margolis CA, Gao W, Voss MH, Li W, Martini DJ, et al. Genomic correlates of response to immune checkpoint therapies in clear cell renal cell carcinoma. Science. 2018;806:801-6.

64. Wolf Y, Bartok O, Patkar S, Eli GB, Cohen S, Litchfield K, et al. UVB-induced tumor heterogeneity diminishes immune response in melanoma. Cell. 2019; 179:219-35.

65. Goodall J, Carreira S, Denat L, Kobi D, Davidson I, Nuciforo P, et al. Brn-2 represses microphthalmia-associated transcription factor expression and marks a distinct subpopulation of microphthalmia-associated transcription factor-negative melanoma cells. Cancer Res. 2008;68:7788-94.

66. Haq R, Shoag J, Andreu-Perez P, Yokoyama S, Edelman H, Rowe GC, et al. Oncogenic BRAF regulates oxidative metabolism via PGC1alpha and MITF. Cancer Cell. 2013;23:302-15.

67. Ribas A, Lawrence D, Atkinson V, Agarwal S, Miller WH, Carlino MS, et al. Combined BRAF and MEK inhibition with PD-1 blockade immunotherapy in BRAF-mutant melanoma. Nat Med. 2019;25:936-40.

68. Homet Moreno B, Mok S, Comin-Anduix B, Hu-Lieskovan S, Ribas A. Combined treatment with dabrafenib and trametinib with immune-stimulating antibodies for BRAF mutant melanoma. Oncoimmunology. 2016;5:1-8.

69. Zhang N, Dou Y, Liu L, Zhang X, Liu X, Zeng Q, et al. SA-49, a novel aloperine derivative, induces MITF-dependent lysosomal degradation of PDL1. EBioMedicine. 2019;40:151-62.

70. Papaccio F, Della Corte CM, Viscardi G, Di Liello R, Esposito G, Sparano F, et al. HGF/MET and the immune system: relevance for cancer immunotherapy. Int J Mol Sci. 2018;19:3595.

71. Glodde N, Bald T, van den Boorn-Konijnenberg D, Nakamura K, O'Donnell JS, Szczepanski S, et al. Reactive neutrophil responses dependent on the receptor tyrosine kinase c-MET limit Cancer immunotherapy. Immunity. 2017:47:789-802.

72. Ferrucci PF, Gandini S, Battaglia A, Alfieri S, Di Giacomo AM, Giannarelli D, et al. Baseline neutrophil-to-lymphocyte ratio is associated with outcome of ipilimumab-treated metastatic melanoma patients. Br J Cancer. 2015;112: 1904-10.

73. Gebhardt C, Sevko A, Jiang H, Lichtenberger R, Reith M, Tarnanidis K, et al. Myeloid cells and related chronic inflammatory factors as novel predictive markers in melanoma treatment with ipilimumab. Clin Cancer Res. 2015;21: 5453-9. 
74. Shen F, Tang X, Wang Y, Yang Z, Shi X, Wang C, et al. Phenotype and expression profile analysis of Staphylococcus aureus biofilms and planktonic cells in response to licochalcone a. Appl Microbiol Biotechnol. 2015;99:359-73.

75. Beuret L, Flori E, Denoyelle C, Bille K, Busca R, Picardo M, et al. Up-regulation of MET expression by a-melanocyte-stimulating hormone and MITF allows hepatocyte growth factor to protect melanocytes and melanoma cells from apoptosis. J Biol Chem. 2007;282:14140-7.

76. McGill GG, Haq R, Nishimura EK. Fisher DE c-Met expression is regulated by Mitf in the melanocyte lineage. J Biol Chem. 2006;281:10365-73.

77. Aguissa-Touré AH, Li G. Genetic alterations of PTEN in human melanoma. Cell Mol Life Sci. 2012;69:1475-91.

78. Bucheit AD, Chen G, Siroy A, Tetzlaff M, Broaddus R, Milton D, et al. Complete loss of PTEN protein expression correlates with shorter time to brain metastasis and survival in stage IIIB/C melanoma patients with BRAFV600 mutations. Clin Cancer Res. 2014:20:5527-36.

79. Peng W, Chen JQ, Liu C, Malu S, Creasy C, Tetzlaff MT, et al. Loss of PTEN promotes resistance to $T$ cell-mediated immunotherapy. Cancer Discov. 2016;6:202-16

80. Bonvin E, Falletta P, Shaw H, Delmas V, Goding CR. A phosphatidylinositol 3kinase-Pax3 axis regulates Brn-2 expression in melanoma. Mol Cell Biol. 2012:32:4674-83.

81. Pinner S, Jordan P, Sharrock K, Bazley L, Collinson L, Marais R, et al. Intravital imaging reveals transient changes in pigment production and Brn2 expression during metastatic melanoma dissemination. Cancer Res. 2009;69: 7969-77.

82. Khaled M, Larribere L, Bille K, Ortonne J-P, Ballotti R, Bertolotto C. Microphthalmia associated transcription factor is a target of the Phosphatidylinositol-3-kinase pathway. J Invest Dermatol. 2003;121:831-6.

83. Kim KH, Seol HJ, Kim EH, Rheey J, Jin HJ, Lee Y, et al. Wnt/B-catenin signaling is a key downstream mediator of MET signaling in glioblastoma stem cells. Neuro-Oncology. 2013;15:161-71.

84. Purcell $\mathrm{R}$, Childs M, Maibach R, Miles C, Turner C, Zimmermann A, et al. HGF/c-met related activation of -catenin in hepatoblastoma. J Exp Clin Cancer Res. 2011;30:96.

85. Monga SPS, Mars WM, Pediaditakis P, Bell A, Mulé K, Bowen WC, et al. Hepatocyte growth factor induces Wnt-independent nuclear translocation of $\beta$-catenin after met- $\beta$-catenin dissociation in hepatocytes. Cancer Res. 2002:62:2064-71.

86. Spranger S, Bao R, Gajewski TF. Melanoma-intrinsic $\beta$-catenin signalling prevents anti-tumour immunity. Nature. 2015;523:231-5.

87. Trujillo JA, Luke JJ, Zha Y, Segal JP, Ritterhouse LL, Spranger S, et al. Secondary resistance to immunotherapy associated with $\beta$-catenin pathway activation or PTEN loss in metastatic melanoma. J Immunother Cancer. J ImmunoTher Cancer. 2019:7:1-11.

88. Luke JJ, Bao R, Sweis RF, Spranger S, Gajewski TF. WNT/b-catenin pathway activation correlates with immune exclusion across human cancers. Clin Cancer Res. 2019;25:3074-83.

89. Delmas V, Beermann F, Martinozzi S, Carreira S, Ackermann J, Kumasaka M, et al. Beta-catenin induces immortalization of melanocytes by suppressing p16INK4a expression and cooperates with N-Ras in melanoma development. Genes Dev. 2007;21:2923-35.

90. Widlund HR, Horstmann MA, Price ER, Cui J, Lessnick SL, Wu M, et al. Betacatenin-induced melanoma growth requires the downstream target Microphthalmia-associated transcription factor. J Cell Biol. 2002;158:1079-87.

91. Yasumoto K, Takeda K, Saito H, Watanabe K, Takahashi K, Shibahara S. Microphthalmia-associated transcription factor interacts with LEF-1, a mediator of Wnt signaling. EMBO J. 2002;21:2703-14.

92. Saito H, Yasumoto K, Takeda K, Takahashi K, Fukuzaki A, Orikasa S, et al. Melanocyte-specific microphthalmia-associated transcription factor isoform activates its own gene promoter through physical interaction with lymphoid-enhancing factor 1. J Biol Chem. 2002;277:28787-94.

93. Schepsky A, Bruser K, Gunnarsson GJ, Goodall J, Hallsson JH, Goding CR, et al. The microphthalmia-associated transcription factor Mitf interacts with beta-catenin to determine target gene expression. Mol Cell Biol. 2006;26: 8914-27.

94. Goodall J, Martinozzi S, Dexter TJ, Champeval D, Carreira S, Larue L, et al. Brn-2 expression controls melanoma proliferation and is directly regulated by beta-catenin. Mol Cell Biol. 2004;24:2915-22.

95. Harris ML, Fufa TD, Palmer JW, Joshi SS, Larson DM, Incao A, et al. A direct link between MITF, innate immunity, and hair graying. PLoS Biol. 2018;16: e2003648.
96. Praetorius C, Grill C, Stacey SN, Metcalf AM, Gorkin DU, Robinson KC, et al. A polymorphism in IRF4 affects human pigmentation through a tyrosinasedependent MITF/TFAP2A pathway. Cell. 2013;155:1022-33.

97. Ueno N, Nishimura N, Ueno S, Endo S, Tatetsu H, Hirata S, et al. PU.1 acts as tumor suppressor for myeloma cells through direct transcriptional repression of IRF4. Oncogene. 2017;36:4481-97.

98. Webster DE, Barajas B, Bussat RT, Yan KJ, Neela PH, Flockhart RJ, et al. Enhancer-targeted genome editing selectively blocks innate resistance to oncokinase inhibition. Genome Res. 2014;24:751-60.

99. Anderson AC, Joller N, Kuchroo VK. Functions in immune regulation. Immunity. 2017;44:989-1004.

100. Mazzarella L, Duso BA, Trapani D, Belli C, D'Amico P, Ferraro E, et al. The evolving landscape of 'next-generation' immune checkpoint inhibitors: a review. Eur J Cancer. 2019;117:14-31.

101. Derré L, Rivals JP, Jandus C, Pastor S, Rimoldi D, Romero P, et al. BTLA mediates inhibition of human tumor-specific CD8+ T cells that can be partially reversed by vaccination. J Clin Invest. 2010;120:157-67.

102. Malissen N, Macagno N, Granjeaud S, Granier C, Moutardier V, GaudyMarqueste $\mathrm{C}$, et al. HVEM has a broader expression than PD-L1 and constitutes a negative prognostic marker and potential treatment target for melanoma. Oncoimmunology. 2019;8:1-14.

103. Yu X, Zheng Y, Mao R, Su Z, Zhang J. BTLA/HVEM signaling: milestones in research and role in chronic hepatitis B virus infection. Front Immunol. 2019; 10:1-8.

104. Landsberg J, Kohlmeyer J, Renn M, Bald T, Rogava M, Cron M, et al. Melanomas resist T-cell therapy through inflammation-induced reversible dedifferentiation. Nature. 2012;490:412-6.

105. Soudja SM, Wehbe M, Mas A, Chasson L, De Tenbossche CP, Huijbers I, et al Tumor-initiated inflammation overrides protective adaptive immunity in an induced melanoma model in mice. Cancer Res. 2010;70:3515-25.

106. Mehta A, Kim YJ, Robert L, Tsoi J, Berent-maoz B, Cochran AJ, et al. Immunotherapy resistance by inflammation-induced dedifferentiation. Cancer Discov. 2019;8:935-43.

107. Riesenberg S, Groetchen A, Siddaway R, Bald T, Reinhardt J, Smorra D, et al. MITF and C-Jun antagonism interconnects melanoma dedifferentiation with pro-inflammatory cytokine responsiveness and myeloid cell recruitment. Nat Commun. 2015;6:8755

108. Englaro W, Bahadoran P, Bertolotto C, Buscà R, Dérijard B, Livolsi A et al. Tumor necrosis factor alpha-mediated inhibition of melanogenesis is dependent on nuclear factor kappa B activation. Oncogene. 1999;18: 1553-9.

109. Bertrand F, Montfort A, Marcheteau E, Imbert C, Gilhodes J, Filleron T, et al. TNFa blockade overcomes resistance to anti-PD-1 in experimental melanoma. Nat Commun. 2017:8:2256.

110. Le Poole IC, Riker Al, Quevedo ME, Stennett LS, Wang E, Marincola FM, et al. Interferon- $\gamma$ reduces melanosomal antigen expression and recognition of melanoma cells by cytotoxic T cells. Am J Pathol. 2002;160:521-8.

111. Gollob JA, Sciambi CJ, Huang Z, Dressman HK. Gene expression changes and signaling events associated with the direct antimelanoma effect of IFNү. Cancer Res. 2005;65:8869-77.

112. Kholmanskikh O, Van Baren N, Brasseur F, Ottaviani S, Vanacker J, Arts N, et al. Interleukins $1 a$ and $1 \beta$ secreted by some melanoma cell lines strongly reduce expression of MITF-M and melanocyte differentiation antigens. Int J Cancer. 2010;127:1625-36.

113. Arts N, Cané S, Hennequart M, Lamy J, Bommer G, Den VEB, et al. MicroRNA-155, induced by interleukin-1 $\beta$, represses the expression of microphthalmia-associated transcription factor (MITF-M) in melanoma cells. PLoS One. 2015;10:1-18.

114. Ohanna M, Giuliano S, Bonet C, Imbert V, Hofman V, Zangari J, et al. Senescent cells develop a PARP-1 and nuclear factor-\{kappa\}B-associated secretome (PNAS). Genes Dev. 2011;25:1245-61.

115. Kamaraju AK, Bertolotto C, Chebath J, Revel M. Pax3 down-regulation and shut-off of melanogenesis in melanoma B16/F10.9 by interleukin-6 receptor signaling. J Biol Chem. 2002;277:15132-41.

116. Khalili JS, Liu S, Rodríguez-cruz TG, Whittington M, Liu C, Zhang M, et al. Oncogenic BRAF(V600E) promotes stromal cell-mediated immunosuppression via induction of Interleukin-1 in melanoma. Clin Cancer Res. 2013;18:5329-40.

117. Gide TN, Quek C, Menzies AM, Tasker AT, Shang P, Holst J, et al. Distinct immune cell populations define response to anti-PD-1 Monotherapy and anti-PD-1/anti-CTLA-4 combined therapy. Cancer Cell. 2019;35:238-55. 
118. Pastorekova S, Gillies RJ. The role of carbonic anhydrase IX in cancer development: links to hypoxia, acidosis, and beyond. Cancer Metastasis Rev. 2019;38:65-77

119. Feige E, Yokoyama S, Levy C, Khaled M, Igras V, Lin RJ, et al. Hypoxiainduced transcriptional repression of the melanoma-associated oncogene MITF. Proc Natl Acad Sci U S A. 2011;108:E924-33.

120. Guerra L, Bonetti L, Brenner D. Metabolic modulation of immunity: a new concept in Cancer immunotherapy. Cell Rep. 2020;32:107848.

121. Ohanna M, Cerezo M, Nottet N, Bille K, Didier R, Beranger G, et al. Pivotal role of NAMPT in the switch of melanoma cells toward an invasive and drug-resistant phenotype. Genes Dev. 2018;32:448-61.

122. Uyttenhove C, Pilotte L, Theate I, Stroobant V, Colau D, Parmentier N, et al. Evidence for a tumoral immune resistance mechanism based on tryptophan degradation by indoleamine 2,3-dioxygenase. Nat Med. 2003:9:1269-74

123. Gopalakrishnan V, Spencer CN, Nezi L, Reuben A, Andrews MC, Karpinets TV et al. Gut microbiome modulates response to anti-PD-1 immunotherapy in melanoma patients. Science. 2018;359:97-103.

124. Li Y, Tinoco R, Elmén L, Segota I, Xian Y, Fujita Y, et al. Gut microbiota dependent anti-tumor immunity restricts melanoma growth in Rnf5 -/mice. Nat Commun. 2019:10:1492

125. Vétizou M, Pitt JM, Daillère R, Lepage $P$, Waldschmitt N, Flament $C$, et al. Anticancer immunotherapy by $C T L A-4$ blockade relies on the gut microbiota. Science. 2015;350:1079-84.

126. Sivan A, Corrales L, Hubert N, Williams JB, Aquino-Michaels K, Earley ZM, et al. Commensal Bifidobacterium promotes antitumor immunity and facilitates anti-PD-L1 efficacy. Science. 2015;350:1084-9.

127. Durinck S, Stawiski EW, Pavía-Jiménez A, Modrusan Z, Kapur P, Jaiswal BS, et al. Spectrum of diverse genomic alterations define non-clear cell renal carcinoma subtypes. Nat Genet. 2015;47:13-21.

128. Boilève A, Carlo MI, Barthélémy P, Oudard S, Borchiellini D, Voss MH, et al. Immune checkpoint inhibitors in MITF family translocation renal cell carcinomas and genetic correlates of exceptional responders. J Immunother Cancer. 2018:6:1-10

129. La Shu S, Paruchuru LB, Tay NQ, Chua YL, Yun Foo AS, Yang CM, et al. Ap4A Regulates Directional Mobility and Antigen Presentation in Dendritic Cells. iscience. 2019;16:524-34.

130. Kitamura $Y$, Morii E, Jippo T, Ito A. mi-transcription factor as a regulator of mast cell differentiation. Int J Hematol. 2000;71:197-202.

131. Morii E, Oboki K, Ishihara K, Jippo T, Hirano T, Kitamura Y. Roles of MITF for development of mast cells in mice: effects on both precursors and tissue environments. Blood. 2004;104:1656-61.

132. St. John AL, Abraham SN. Innate immunity and its regulation by mast cells. J Immunol. 2013;190:4458-63.

133. Biswas PS, Gupta S, Stirzaker RA, Kumar V, Jessberger R, Lu T, et al. Dual regulation of IRF4 function in $T$ and $B$ cells is required for the coordination of T-B cell interactions and the prevention of autoimmunity. J Exp Med. 2012;209:581-96.

134. Simonetti G, Carette A, Silva K, Wang H, De Silva NS, Heise N, et al. IRF4 controls the positioning of mature $B$ cells in the lymphoid microenvironments by regulating NOTCH2 expression and activity. J Exp Med. 2013;210:2887-902

135. Lin L, Gerth AJ, Peng SL. Active inhibition of plasma cell development in resting $B$ cells by microphthalmia-associated transcription factor. J Exp Med. 2004:200:115-22.

136. Zhang S, Yue X, Yu J, Wang H, Liu B. MITF regulates downstream genes in response to vibrio parahaemolyticus infection in the clam meretrix petechialis. Front Immunol. 2019;10:1-12.

137. Sahin U, Oehm P, Derhovanessian E, Jabulowsky RA, Vormehr M, Gold M, et al. An RNA vaccine drives immunity in checkpoint-inhibitor-treated melanoma. Nature. 2020;585:107-12.

138. Wiedemann GM, Aithal C, Kraechan A, Heise C, Cadilha BL, Zhang J, et al. Microphthalmia-associated transcription factor (MITF) regulates immune cell migration into melanoma. Transl Oncol. 2019;12:350-60.

139. Yannay-Cohen N, Carmi-Levy I, Kay G, Yang CM, Han JM, Kemeny DM, et al. LysRS serves as a key signaling molecule in the immune response by regulating gene expression. Mol Cell. 2009;34:603-11.

140. Wahab SZ, Yang DCH. Synthesis of diadenosine-5',5"'-P1,P4-tetraphosphate by lysyl-tRNA synthetase and a multienzyme complex of aminoacyl-tRNA synthetases from rat liver. J Biol Chem. 1985;260:5286-9.
141. Motzik A, Amir E, Erlich T, Wang J, Kim BG, Han JM, et al. Post-translational modification of HINT1 mediates activation of MITF transcriptional activity in human melanoma cells. Oncogene. 2017;36:4732-8.

142. Pérez-Guijarro E, Yang HH, Araya RE, El Meskini R, Michael HT, Vodnala SK, et al. Multimodel preclinical platform predicts clinical response of melanoma to immunotherapy. Nat Med. 2020;26:781-91.

143. Hugo W, Shi H, Sun L, Piva M, Song C, Kong X, et al. Non-genomic and immune evolution of melanoma acquiring MAPKi resistance. Cell. 2015;162: 1271-85.

144. Bertolotto C, Abbe P, Hemesath TJ, Bille K, Fisher DE, Ortonne J-P, et al. Microphthalmia gene product as a signal transducer in CAMP-induced differentiation of melanocytes. J Cell Biol. 1998;142:827-35.

145. Price ER, Horstmann MA, Wells AG, Weilbaecher KN, Takemoto CM, Landis $\mathrm{MW}$, et al. Alpha-melanocyte-stimulating hormone signaling regulates expression of microphthalmia, a gene deficient in Waardenburg syndrome. J Biol Chem. 1998;273:33042-7.

146. Saez-Ayala M, Montenegro MF, Sanchez-Del-Campo L, Fernandez-Perez MP, Chazarra S, Freter R, et al. Directed phenotype switching as an effective antimelanoma strategy. Cancer Cell. 2013;24:105-19.

\section{Publisher's Note}

Springer Nature remains neutral with regard to jurisdictional claims in published maps and institutional affiliations.

\section{Ready to submit your research? Choose BMC and benefit from:}

- fast, convenient online submission

- thorough peer review by experienced researchers in your field

- rapid publication on acceptance

- support for research data, including large and complex data types

- gold Open Access which fosters wider collaboration and increased citations

- maximum visibility for your research: over $100 \mathrm{M}$ website views per year

At BMC, research is always in progress.

Learn more biomedcentral.com/submissions 